Synthesis of Natural

Products and

Potential Drugs

\section{Synthesis of $(+)$-Biotin}<smiles>CC(=O)OC1CSCC1NC(C)C</smiles>
dimethyl ester

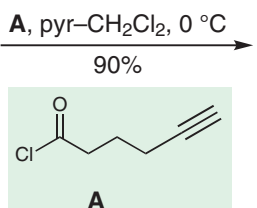

A<smiles>C#CCCCC(=O)NC(C)CSCC</smiles>

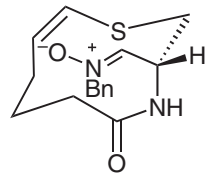

$\mathbf{F}$
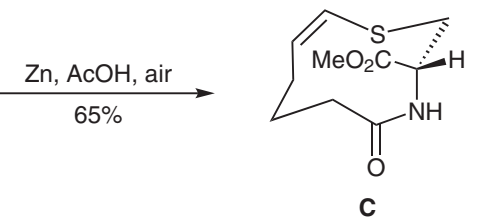

c
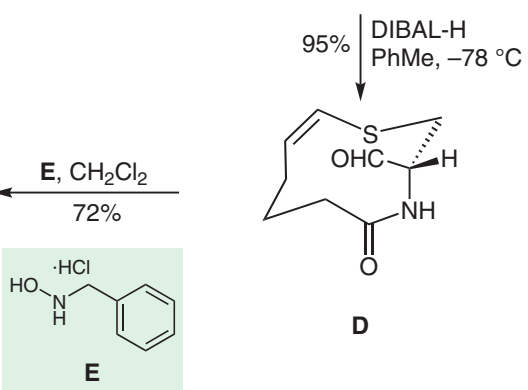

D

\section{Key words}

\section{(+)-biotin}

disulfide cleavage

dipolar cycloaddition

nitrone-olefin cycloaddition
Significance: $(+)$-Biotin is a vitamin involved in several biological processes including acetyl-CoA carboxylase mediated carboxylation of acetyl-CoA to malonyl-CoA. (+)-Biotin forms one of the strongest known non-covalent interactions with the protein streptavidin. In biotechnology, this binding is widely used for the labeling of proteins and small molecules and protein purification. Starting from L-cystine dimethyl ester, Baggiolini and co-workers reported an elegant synthesis of (+)-biotin, which features a highly diastereoselective intramolecular dipolar cycloaddition.
Comment: Acylation of L-cystine dimethyl ester with 5-hexynoyl chloride (A) afforded amide $\mathbf{B}$. Treatment of $\mathbf{B}$ with zinc in $\mathrm{AcOH}$ under air atmosphere led to disulfide cleavage and subsequent cyclization to furnish C. DIBAL-H reduction of the ester moiety followed by condensation of the resulting aldehyde with hydroxylamine $\mathbf{E}$ gave nitrone $\mathbf{F}$. Nitrone-olefin cycloaddition was induced by refluxing $\mathbf{F}$ in toluene. Reductive $\mathrm{N}-\mathrm{O}$ cleavage followed by treatment with methyl chloroformate (H) afforded carbamate $\mathbf{I}$. $\mathrm{Ba}(\mathrm{OH})_{2}$-mediated amide hydrolysis led to concomitant urea formation. Dehydroxylation of $\mathrm{j}$ in two steps followed by global deprotection furnished (+)-biotin. 